\title{
Experimental-Phonetic Analysis of Rhythmic Structures in the English Language
}

\author{
Javahir Yagubova $^{1}$ \\ ${ }^{1}$ Azerbaijan University of Languages, Baku, Azerbaijan \\ Correspondence: Javahir Yagubova, Azerbaijan University of Languages, Baku, Azerbaijan. E-mail: \\ jewel75@mail.ru
}

Received: May 26, 2015 Accepted: June 25, 2015 Online Published: July 30, 2015

doi:10.5539/ijel.v5n4p137 URL: http://dx.doi.org/10.5539/ijel.v5n4p137

\begin{abstract}
The article has been written on the basis of experimental-phonetic method in the study of rhythmic structures in the English language. The main aim of the investigation is to define and systematize the inner laws of the language and to show their role in the formation of rhythmic groups, as well as, to analyse the acoustic parameters and prosodic features of rhythmic structures and interrelation of components in their intonation. For the purpose of investigation we preferred to choose dialogical texts (particularly political talk shows) recorded from American TV Channel CNN and some other dialogues. In order to measure the acoustic parameters of the rhythmical groups the computer program PRAAT has been used.
\end{abstract}

Keywords: rhythmic structures, prosody, syllable, proclitic, enclitic, acoustic parameters

\section{Introduction}

In the introduction of the article it is pointed out rhythmic structures of the utterances in the English texts have been investigated from the experimental-phonetic aspect. The author of the article has made an attempt to highlight the prosodic features (frequency, intensity, time) of rhythmic groups, and to show their role in the formation of rhythmic structures. She has also introduced linguists' different approaches to the problem of rhythm within the frames of metrical phonology. Despite much excellent work has been done on such topic as rhythm, the experimental-phonetic analysis of rhythmic groups has received little investigation. In the article the author has introduced the tables indicating prosodic features of rhythmic groups.

In the conclusion of the research the author tried to generalize her considerations obtained from the result of the investigation.

\section{Scope of the Study}

Discourse on how globalization affects language, increasingly discusses the idea of language learning and what it means is to analyse every aspect of the language thoroughly.

The traits of the language learning involve such aspects as phonology, morphology, syntax and so on. The study of intonation, as one of the most important fields of phonology, is considered to be of great importance in linguistics. Though there have been many approaches to intonation, none of them can be satisfying, as one of them highlights the acoustic, the other the articulatory, and the third one the emotional aspect of intonation (Veysalli, 2009). However, all the definitions accept the fact, that intonation is the complex unity of certain components, as melody, stress, rhythm, tempo and pause.

The total meaning of an act of speech and information transmitting depends on a number of language signals, among which rhythm is considered to be one of the most important. In the act of speech rhythm regulates it by means of alternation of language units at a relatively equal period of time. The alternation of speech elements as syllable, stress, rhythmic group is not accidental, all is carried out with the principle of geometric range: $a: b=b: c=c: d$ and so on (Mahnken, 1953). This feature of the rhythm evokes different emotional-esthetic feelings in a man which is observed both in poetry and prose. It is worth noting that rhythmically properly organized speech makes it better understood than that where rhythm is broken. Abercrombie was the first who paid attention to the phenomenon in which "rhythmic beating" is formed between interlocutors. He writes "When starting the conversation each member of the dialogue tries to keep on the " rhythmic beating" already formed, in other words, he is tuned up to the rhythm of his interlocutor." (Andreyeva, 1978). 
For Mechonic rhythm is the "movement" that acts in all aspects of the language, it is the movement of the meaning in speech, it is the organization of meaning in the discourse. For him, if the meaning of the speech is the result of speech activity, then rhythm is its realization (Meschonnic, 1982).

Yespersen characterizes rhythm in the following way "Rhythm plays a great part in ordinary life, apart from poetry and prose. We can see it in the combination of monosyllable and disyllable by means of and, where monosyllable is placed first in order to make the rhythm as aa aa instead of aaa a. That is why it is preferable to pronounce the expressions like "bread and butter", "cups and saucers", "head and shoulders", rather than "butter and bread", "saucers and cups" and so on (Selkrik, 1986).

The problem of rhythm is well explained in the level of metrical phonology, where exist two fundamental theories ( "tree theory" and "grid theory" ), based on generative phonology, which was founded by American linguists. These theories clearly explain the morphosyntactic structure of a word, as well as, rhythmical variations on the ground of transformational rules.

It is worth mentioning that the number of the rhythmic groups in the utterance depends on the number of the stressed syllables. The nuclear of every rhythmic group is the stressed syllable, while unstressed syllables are either in proclitic or enclitic relations with the stressed ones. Unstressed syllables can join the stressed syllables in two ways, 1) semantically, f. eg. Mary/ is leaving/tomorrow/; 2) by hanging on to the preceding stressed syllables enclitically, e.g. Mary is/ leaving to/morrow/

This is probably a generalization that holds for all stressed-timed languages, including English.

\section{Research Methodology}

For the analysis of rhythmic structures in the English language observational, linguistic and experimental-phonetic methods have been used in the article. Experimental techniques are widely used in linguistics, especially in those fields that have been influenced by the methods of sciences where experimentation is routine. The experiments can be held in two methods: the subjective method which is realized by listening and the objective method realized with the help of special machines. Depending on the purpose of the experiment, the author has given priority to the second method, making oscillagraphic and spectrographic analyses. Doing it she considered many factors - whether two people, small groups or large-groups of people are interacting. Age, sex, social background, the topic of the conversation, and the characteristics of the social setting (e.g., level of formality) have also been taken into consideration in the experiment.

\section{Experimental-Phonetic Analysis of Rhythmic Structures in the English Language}

In linguistics the term "prosody" has been used in a number of different ways in different contexts, though there is none the less a clear common element in each. The reason of this can be explained with the fact that "prosody" has always been accepted as a "periferial" aspect of the language, and it was considered a more difficult aspect of the language than the others (Lyons, 1987).

More recently, reviews of physiological and acoustic work in phonetics and development in the fields of computer technology and science have given us a great opportunity to investigate prosody and prosodic features visually.

Thus, the physical indicators of prosody are fundamental Frequency $\left(\mathrm{F}_{0}\right)$, Time $(\mathrm{T})$ and Intensity $(\mathrm{Db})$ Prosody is a model that is formed by means of these three factors, this model, in its turn, forms the melodic structure and rhythm of the utterance.

Despite these factors are equally important, some linguists give privilege to melody. Sherba writes "Though melody can not exist alone, we must admit its independence in the language." (Sherba, 1958) The main idea of Sherba' s conception implies the fact that melody dominates in the rhythmical arrangement of the utterance. It serves to express different shades of meaning and helps to the segmentation of the act of speech.

The aim of the investigation is to analyse the prosodical peculiarities of the rhythmic groups on the materials in the English language. Here the following factors have been much paid attention: 1) the number of the syllables in the rhythmic groups (stressed and unstressed); 2) the number ratio of stressed and unstressed syllables; 3 ) the position of the syllables in the rhythmic groups; 4 ) the borders of the rhythmic groups. The material consisting of the dialogical texts was sounded by native speakers.

The experimental-phonetic analysis of the material can be explained this way:

"I have an interview tomorrow" /aI 'hæv ən 'Intəvju: tə,mbrou//

The acoustic parameters are shown as follows: 
average relative time: $114-96-133 \mathrm{~m} / \mathrm{sec}$, average arithmetic mark: $114 \mathrm{~m} / \mathrm{sec}$.

averge relative frequency: $286-267-178 \mathrm{hs}$, average arithmetic mark: $243 \mathrm{hs}$.

average relative intensity: 81-76-75 db, average arithmetic mark: $77 \mathrm{db}$.

In the sentence "No, I didn't" /,nou /al , didnt// 2 rhythmic groups were used, the acoustic parameters of which are as following:

average relative time: $176-121 \mathrm{~m} / \mathrm{sec}$, average arithmetic mark: $139 \mathrm{~m} / \mathrm{sec}$.

average relative freguency: $240-232 \mathrm{hs}$, average arithmetic mark: $236 \mathrm{hs}$.

average relative intensity: $82-81 \mathrm{db}$, average arithmetic mark: $81 \mathrm{db}$.

The acoustic parameters of the sentence "We are all going to have great interview" /wi a·r 'J:1 'gourn to hæv 'g reIt , Intəvju://, containing 4 rhythmic groups are as following:

average relative time: $115-102-126-94 \mathrm{~m} / \mathrm{sec}$, average arithmetic mark: $108 \mathrm{~m} / \mathrm{sec}$. average relative freguency: 250-237-202-190 hs, average arithmetic mark: $219 \mathrm{~h}$. average relative intensity: 79-78-81-74 db, average arithmetic mark: $78 \mathrm{db}$.

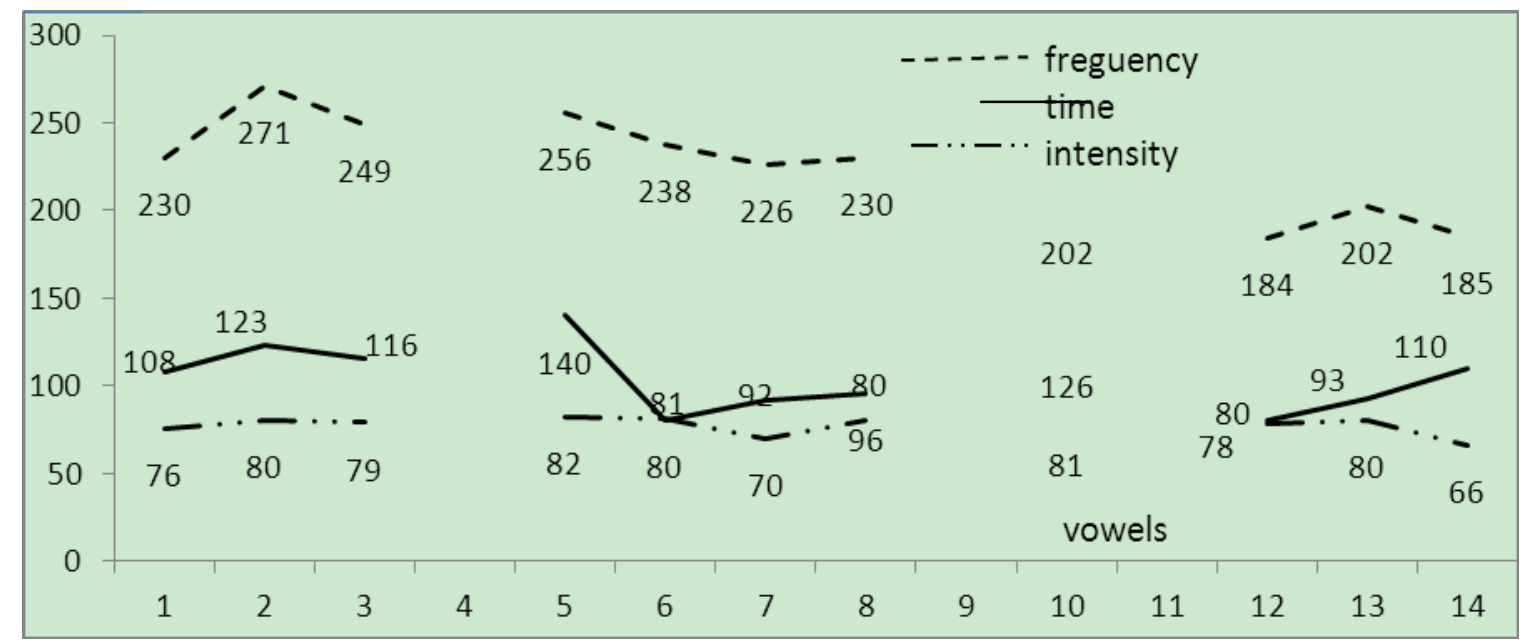

In the sentence "I voted for Obama" /aI 'voutıd fər $\mathrm{b}$, bımə// again 2 rhythmic groups are realized. Their acoustic parameters are as following:

average relative time: $110-105 \mathrm{~m} / \mathrm{sec}$, average arithmetic mark: $107 \mathrm{~m} / \mathrm{sec}$.

average relative freguency: 220-182 hs, average arithmetic mark: $201 \mathrm{hs}$.

average relative intensity: $83-78 \mathrm{db}$, average arithmetic mark: $81 \mathrm{db}$.

The acoustic parameters of the sentence /a 'voutıd far $\mathrm{b}, \mathrm{b} \Lambda \mathrm{ma} / /$

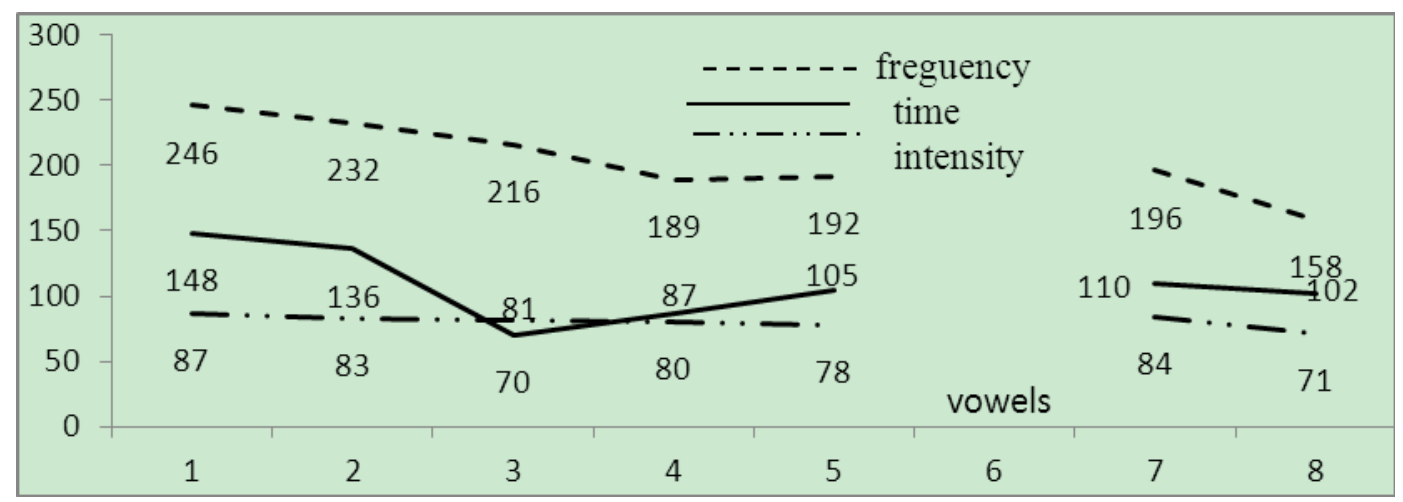


In the sentence "I can't disclose that information" /aI 'ka:nt dis'klouz ðət Infə,meIfn// the acoustic parameters are shown in tis way:

average relative time: $119-113-89 \mathrm{~m} / \mathrm{sec}$, average arithmetic mark: $107 \mathrm{~m} / \mathrm{s}$.

average relative freguency: 298-284-179 hs, average arithmetic mark: $254 \mathrm{hs.}$

average relative intensity: $82-79-80 \mathrm{db}$, average arithmetic mark: $80 \mathrm{db}$.

The acoustic parameters of the sentence /ar 'ka:nt dis'klouz ðət Infə,meIfn// is shown in the following way:

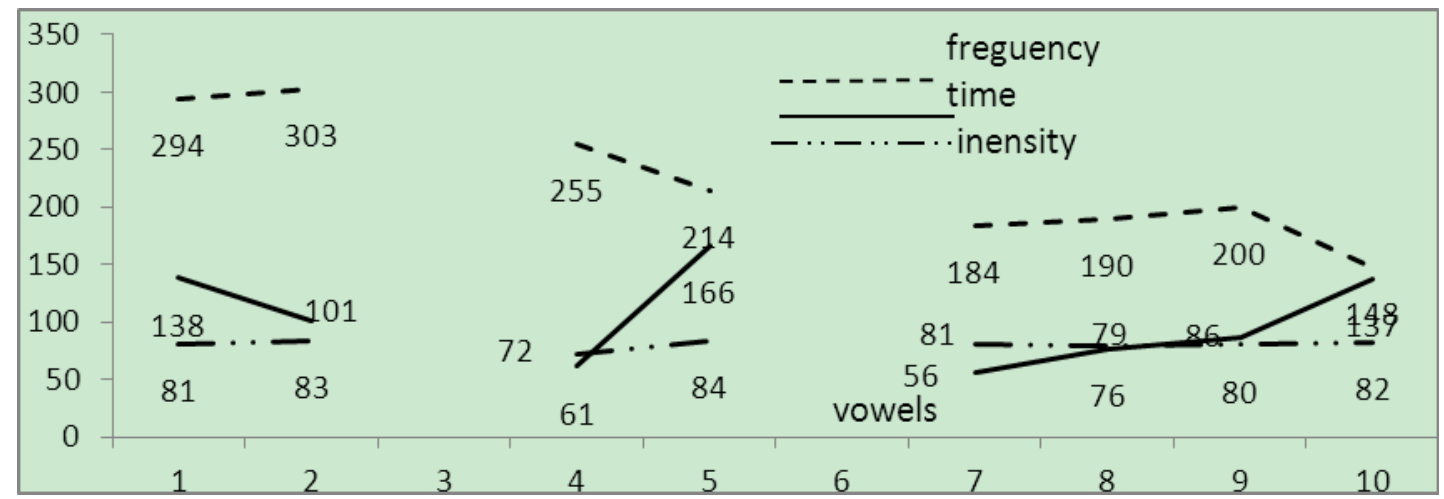

Though many sentences were involved into analysis, we have been able to show only some of them. Thus, in these sentences the rhythmic groups containing 2-3 syllables predominate. The intonational contour of the utterances are due to their melody. The time parameter decreases in 24 cases, increases in 35 . In 15 cases, as rhythmic groups contain only 1 syllable, definition of time parameter was impossible.

In the next step of our investigation we have analysed the acoustic parameters of the rhythmic groups in general guestions.

Thus, in the sentence "Is this the class to prepare for interviews?" ¿Iz 'ðIs ðə 'kla:s tə pri'peə fər 、In(t)əvju:z? There are 4 rhythmic groups, the acoustic parameters in them are shown as following:

average relative time: $77-129-119-108 \mathrm{~m} / \mathrm{sec}$, average arithmetic mark: $108 \mathrm{~m} / \mathrm{sec}$. average relative freguency: 239-259-223-173 hs, average arithmetic mark: $215 \mathrm{hs}$.

average relative intensity: 76-77-73-70 db, average arithmetic mark : $74 \mathrm{db}$

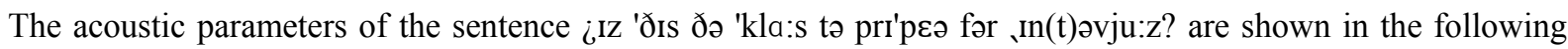
way:

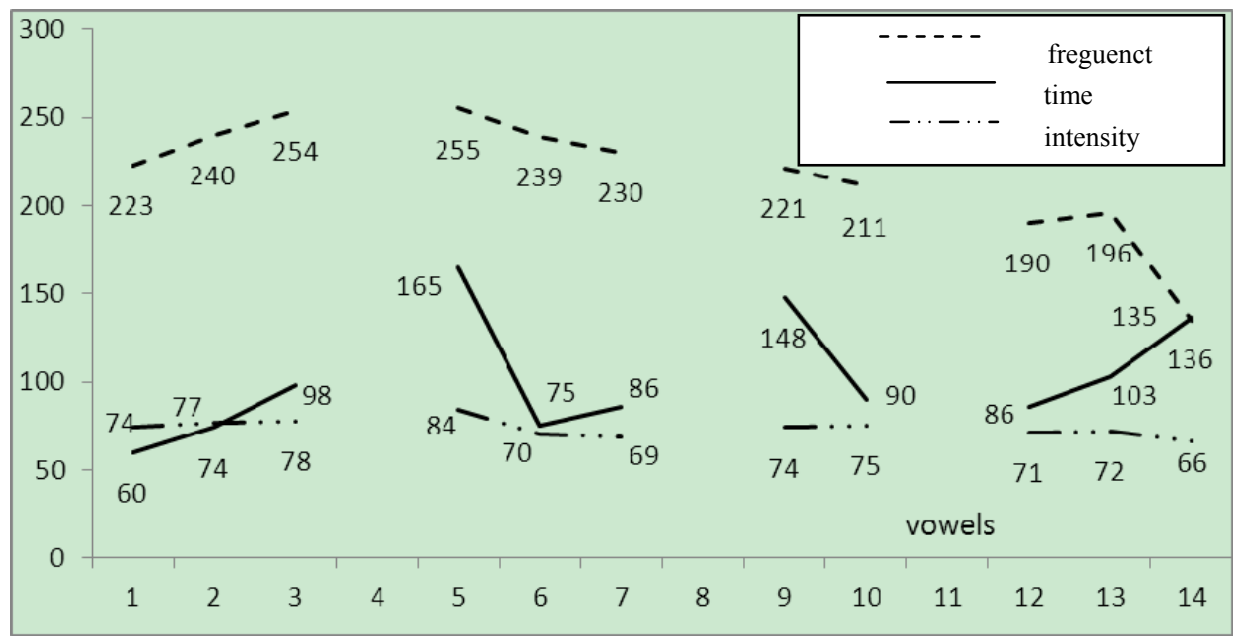


In the sentence "Did you know that they pay as much attention to what you ask as what you say in an interview?

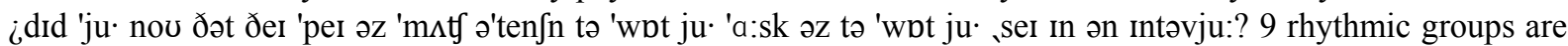
realized, the acoustic parameters are shown as following:

average relative time: 99-109-83-90-93-106-91-93-103 m/sec, average arithmetic mark: $96 \mathrm{~m} / \mathrm{san}$.

average relative freguenvy: 243-223-211-214-212-203-208-190-205 hs, average arithmetic mark: $212 \mathrm{hs.}$

average relative intensity: 78-75-81-82-79-82-80-71-73 db, average arithmetic mark: $77 \mathrm{db}$.

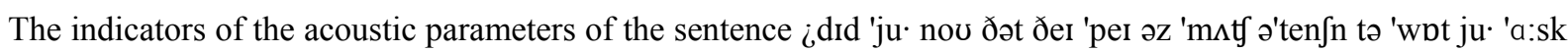
əz tə 'wbt ju' , seI In ən Intəvju:? are shown below:

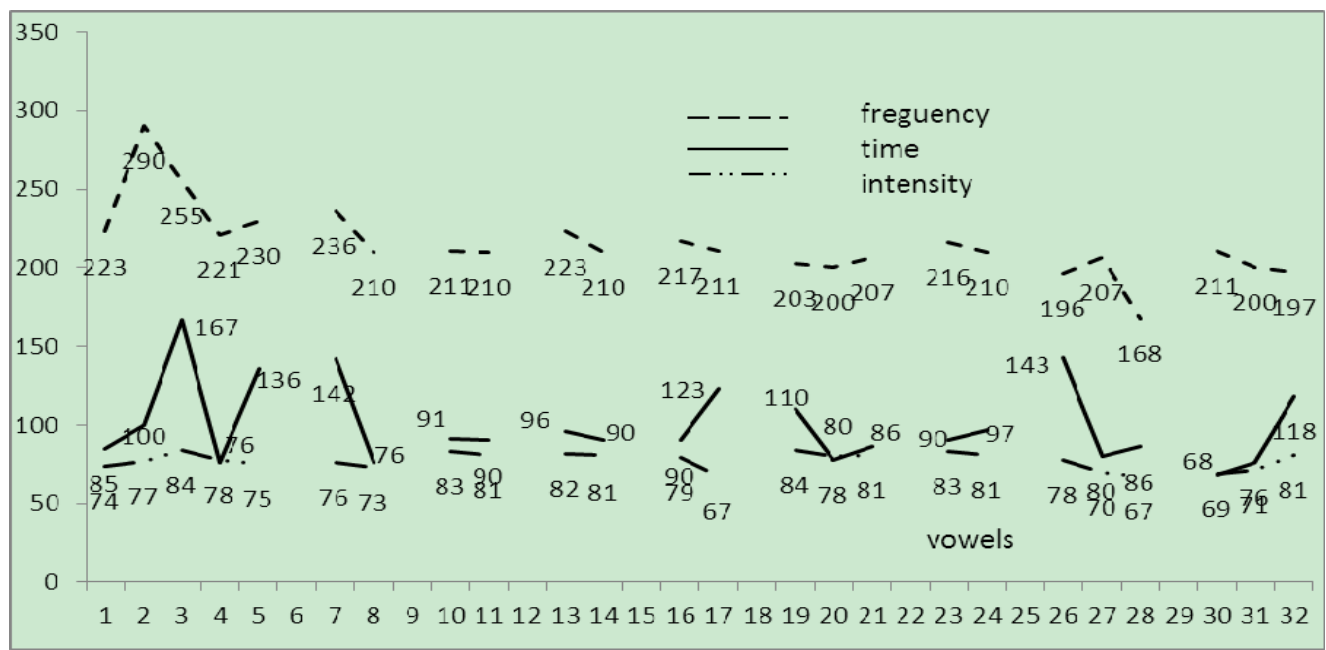

In the sentences with rising melody the cases are a bit different from those of falling melody. In both kinds of sentences rhythmic groups containing 2-3 syllables predominate. Rhythmic groups with more than 4-5 syllables were rarely noticed. The time parameter decreases in 17 cases, increases in 26 cases.

The intensity is increasing in 21 cases, decreasing in 15 cases. The maximum melody is observed in the initial and final rhythmic groups.

The analysis of the special guestions, imperative and exclamatory sentences gives us an opportunity to say that their prosodic features are somehow close to statements with falling melody. E.g. in the sentence "What else should I keep in mind? i'wbt, els fud aI ki:p In mand? the acoustic parameters are shown in the following way:

average relative time: $105-81-151-\mathrm{m} / \mathrm{sec}$, average arithmetic mark $112 \mathrm{~m} / \mathrm{sec}$.

average relative frequency: 231-215-189 hs, average aritmetic mark $211 \mathrm{hs}$.

average relative intensity: 80-80-72 db, average aritmetic mark $77 \mathrm{db}$.

The acoustic parameters of the imperative sentence are shown as following:

"Listen carefully to the questions and be honest in your responses" / 'IIsn 'keəfuli tə ðə, kwestfnz /ənd bi 'bnist In jorrI,spbnsiz//

average relative time: $86-98-81-85-77 \mathrm{~m} / \mathrm{sec}$, average arithmetic mark: $85 \mathrm{~m} / \mathrm{sec}$.

average relative frequancy: 220-199-204-199 hs,average arithmetic mark: $201 \mathrm{hs}$.

average relative intensity:80-78-77-79-76db,average arithmetic mark: $78 \mathrm{db}$.

In the sentences with more than two sintagms the acoustic parameters are explained as following:

"She had to leave her husband alone and she wasn't sure how he was going to handle being alone" / $/ \mathrm{i} \cdot$ 'hæd to

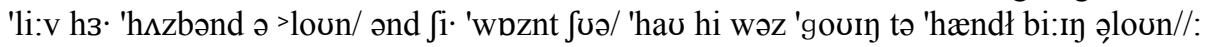

average relative time: 84-101-83-147-99-102-107-168 m/sec, average arithmetic mark: $103 \mathrm{~m} / \mathrm{sec}$.

average relative frequancy:196-231-201-204-199-209-197-203 hs, average arithmetic mark: 205 hs. 
average relative intensity: 83-84-84-82-83-84-81-83 db, average arithmetic mark: $83 \mathrm{db}$. Thus, the first syntagm /fi. 'hæd to 'li:v h3 'hızbənd a >loun/ is accompanied with the increase of all parameters, because this is still the beginning of the information. The pitch melody starts to rise gradually, intensity and frequensy having high parameters as well. In the second syntagm /ond $\int \mathrm{i}$ 'wbznt > $\int \mathrm{v}$ / $/$ we observe the same condition in the acoustic parameters as in the first syntagm, because the speech is not over yet. Only in the last syntagm / 'hav hi wəz 'g ourn to 'hændł bi:In ə,loun / we can feel how the acoustic parameters start to weaken corresponding to the terminal intonation. This is sign to the end of the idea.

The same can be said about the following sentence containing many syntagms.

"So, she gave me a list of questions and asked me if I could check on him and see if, er, he is doing these things"

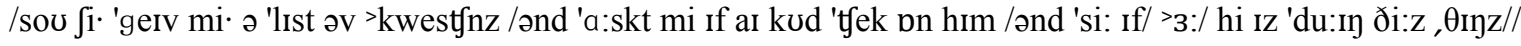

average relative time: $110-83-96-98-115-87-96-167-92-93 \mathrm{~m} / \mathrm{sec}$, verage arithmetic mark: $103 \mathrm{~m} / \mathrm{sec}$.

average relative requency: 236-243-224-200-198-216-218-210-231-213 hs,average arithmetic mark: $218 \mathrm{hs}$.

average relative intensity: 82-82-83-81-83-82-81-85-82-83 db, average arithmetic mark: $82 \mathrm{db}$.

One more thing that should be mentioned is "stress shift" in the English language. Here we observed that despite some words are stressed, became unstressed in some cases, or vice versa. This can only be explained within the rules of metrical phonology, exactly saying, by the transformational rules that were mentioned before.

Both the "grid theory" and "tree theory" explain that the utterance can be "eurythmic" if it contains a row whose marks are spaced close to 2-4 syllables. Thus, in the example "¿Would you prefer a private vehicle? ¿wud 'ju· prr'f3: ə praIvit vi:kəl? the speaker prefers to use rhythmic groups containing equal number of syllables. For that reason he shifts the stress from the word "would" which is generally stressed when introducing Yes/ No questions to the word "you", after which equally organized rhythmic groups are formed.

For their structure rhythmic groups can be simple or compound. The rhythmic groups are perceived clearly in English. This feature of rhythmic groups can be explained for the following factors: 1) isochrony or eurhythmy of the rhythmic groups; 2) the greater distinction of stressed syllables; 3) merging of unstressed syllables to the stressed ones tightly.

\section{Conclusion}

The material involved the experimental-phonetic analysis consists of 98 sentences, 364 rhythmic groups. The analysis of rhythmic structures in the English language helps us to come to the following conclusion:

1) In the formation of rhythmic groups the role of phonological transformation is great. In this sense, the notion "eurhythmy" reflects the principle of rhythmic variations more distinctly. As a result, the reason why stressed syllables are placed at a distance of 2-4 syllables is explained.

2) In the rhythmic arrangement of the text, melody is considered as a main component expressing special pragmatic meaning. Thanks to melody, we can define the communicative type of the sentence.

3) Rhythm performs some functions in the language, the most important of which is its constitutive function. Its main idea is that rhythm forms hierarchic arrangement of the system units. The second function of rhythm is esthetic function which gives special coloring to the speech.

4) The center of every rhythmic group is the stressed syllable, while unstressed syllables hang up to them either proclitically or enclitically.

5) The time spent on the rhythmic groups, containing fewer unstressed syllables increases, but those with more unstressed syllables decreases.

6) In defining rhythmic groups pause is considered as important as stress and melody. But sometimes when the pause is hardly felt, prosodic features can be the only indicator of rhythmic division. E.g. the lengthening of a vowel, the aspiration of a consonant and so on ("my train" or "might rain").

7) The result of the experiment showed that in realization of "dialogical speech" extralinguistic factors are important as well. Such factors include the social-cultural level of the speaker, the interrelation between the speakers, the place where the dialogue takes place and so on.

8) Rhythmic groups are divided into simple and compound groups. During the experiment it was observed that the English tend to use simple rhythmic groups more than the compound ones. The number of the rhythmic groups changes from 1-13. Besides, rhythmic groups give priority to the structures with 2-3 syllables more than to 4-5-6 syllables. The interval between minimum and maximum tone intensity is changeable. This depends on 
the speaker's gender, his emotional status, the number of the syllables and so on. Thus, the acoustic parameters can be shown in the following consequence:

a) The time parameter decreases in 210 cases, increases in 139. It can be explained for the superiority of the simple rhythmic groups. As we mentioned before, the time parameter is asymmetric with the length of the rhythmic groups.

b) The frequency decreases in 249 cases, increases in 139 . The falling tone frequency is mostly observed in the utterances with 2,3,4 syntagms. But in most utterances the frequency is high in the initial position. The simple and the compound tones are used approximately at an equal ratio.

c) Intensity is decreasing in 284 cases, increasing in 80 . This can be explained for the communicative type of the sentence. In the sentences with rising intonation the shortening of the speed in unstressed syllables after the stressed ones is more intensive than in the sentences with falling intonation.

\section{References}

Andreyeva, D. I. (1978). Phonetic Peculiarities of Rhythmic Structures in English (experimental-phonetic analysis). Dissertation.

Crystal, D. (1969). Prosodic Systems and Intonation in English. Cambridge University Press.

Hogg, R. (1987). McCully C.B. Metrical Phonology. Cambridge University Press.

Lyons, J. (1987). New York Horizons in Linguistics. Penguin Books.

Mahnken, I. (1953). Formelemente des Sprechrhythmus. Leitschrift für Phonetic.

Meschonnic, H. (1982). Critique du Rythme. Antropologie historique du Langage. Paris, Verdien.

Selkrik, E. O. (1986). Phonology and Syntax. The Relation between Sound and Structure. Cambridge Mass. MIT. Press.

Sherba, L. V. (1958). Selected works on Linguistics and Phonetics. Nauka.

Veysalli, F. (2009). Selected works. Baku.

\section{Copyrights}

Copyright for this article is retained by the author(s), with first publication rights granted to the journal.

This is an open-access article distributed under the terms and conditions of the Creative Commons Attribution license (http://creativecommons.org/licenses/by/3.0/). 